\title{
The role of red cell distribution width as a noninvasive index for predicting liver cell failure and portal hypertension in cirrhotic patients
}

\author{
Howaida A. Nafady ${ }^{\mathrm{a}}$, Tarek A. Hassan ${ }^{\mathrm{b}}$, Lobna A. Ahmed ${ }^{\mathrm{b}}$, \\ Marina A. Waheeb ${ }^{b}$
}

${ }^{a}$ Clinical Hematology, ${ }^{b}$ Internal Medicine, Assiut University, Egypt

Correspondence to Prof. Howida A. Nafady, Assiut, Egypt, Professor of Internal Medicine and Clinical Hematology, Assiut University, Egypt. Tel: 01094721339 .

e-mail: howaidanafady@yahoo.com

Received 16 July 2018

Accepted 24 July 2018

The Egyptian Journal of Internal Medicine 2018, 30:255-263

\begin{abstract}
The liver distortion that occurs in cirrhosis results in increased resistance to portal blood flow and hence in portal hypertension which is one of the most common and serious complications of liver cirrhosis. Red cell distribution width (RDW) is routinely performed as part of a complete blood cell counts. Elevated RDW values were also shown to be associated with increased risk of mortality in the general population. However, to our knowledge, the role of RDW values predicting LCF and portal hypertension in LC has not been well-defined. The present study was designed to investigate the role of RDW as anon invasive predicting index for LCF and portal hypertension in cirrhotic patient which will improve the diagnostic efficiency and provide useful information with other serum markers for the detection of LCF in LC. We found significantly good correlation between Child-Pugh and RDW values which can ultimately be used to predict the survival of patients with LC. There was also good correlation between RDW and those receiving ?-blockers, so it may be used as an indicator for patient compliance, but there was no significant correlation with the grade of encephalopathy and portal hypertension.
\end{abstract}

\footnotetext{
Keywords: distribution width (RDW)

Egypt J Intern Med 30:255-263

(C) 2019 The Egyptian Journal of Internal Medicine

$1110-7782$
}

complete blood count (CBC), international normalization ratio (INR), liver cirrhosis (LC), liver cell failure (LCF), liver function test (LFT), model for end stage liver disease (MELD), prothrombin time $(\mathrm{PT})$, portal vein $(\mathrm{PV})$, red blood corpusles (RBCs), red blood cell

\section{Introduction}

Cirrhosis is an increasing cause of morbidity and mortality in developing countries, it being the 14th most common cause of death worldwide. It results in 1.03 million deaths per year worldwide [1]. Liver biopsy was used in the diagnosis of liver cirrhosis (LC), but the nature of liver biopsy such as invasiveness, cost, poor compliance, and contraindications restricted the widespread utilization particularly in the follow-up [2]. One of the most common and serious complications of LC is portal hypertension. Portal hypertension is a detrimental complication resulting from the obstruction of portal blood flow, such as cirrhosis or portal vein (PV) thrombosis [3,4]. In LC, increased intrahepatic vascular resistance to the portal flow elevates portal pressure and leads to portal hypertension. Once portal hypertension develops, it influences extrahepatic vascular beds in the splanchnic and systemic circulations, causing collateral vessel formation and arterial vasodilation. This helps to increase the blood flow into the PV. Consequently, esophageal varices or ascites develops.

Red cell distribution width (RDW) is an automated measure of the heterogeneity of red blood cell (RBC) sizes (e.g. anisocytosis) and routinely performed as part of a complete blood cell counts [5-7]. RDW is used in the differential diagnosis of anemia [8]. Recently, a series of studies have demonstrated that RDW can serve as a novel, independent predictor of prognosis in patients with cardiovascular diseases (e.g. heart failure [9-11], stable coronary diseases [12], acute myocardial infarction [13], strokes [14], and pulmonary hypertension [15]). Elevated RDW values were also shown to be associated with increased risk of mortality in the general population [16-18]. However, to our knowledge, the role of RDW values predicting liver cell failure (LCF) and portal hypertension in LC has not been well defined. The present study was designed to investigate the role of $\mathrm{RDW}$ as a noninvasive index for predicting LCF and portal hypertension in cirrhotic patients which will improve the diagnostic efficiency.

This is an open access journal, and articles are distributed under the terms of the Creative Commons Attribution-NonCommercial-ShareAlike 4.0 License, which allows others to remix, tweak, and build upon the work non-commercially, as long as appropriate credit is given and the new creations are licensed under the identical terms. 


\section{Patients and methods}

A total of 147 patients were enrolled in the study. Of them, 108 were men and 39 were women diagnosed as LC in Assiut University Hospital and E1-Rajhi Hospital. LC was diagnosed based on the history, physical examination, biochemical (liver function test, coagulation profile), and ultrasound (US) findings of cirrhosis.

\section{Inclusion criteria}

The patients were diagnosed to be cirrhotic based on history (previously diagnosed to be cirrhotic, presence of esophageal varices diagnosed with previous upper endoscopy, history of previous hepatic encephalopathy), physical examination (ascites, lower limb edema, jaundice, etc.), hypoalbuminemia, prolonged prothrombin time and decrease in prothrombin concentration, serological testing for $\mathrm{HBs} \mathrm{Ag}$ and $\mathrm{HCVAb}$ and cirrhosis findings in abdominal US. Complete blood count including RDW was done for all of them. Medical history was taken from all of them especially receiving $\beta$-blocker or not.

\section{Exclusion criteria}

Evidence of iron deficiency anemia and patients suffering from hematemesis for less than 1 month.

\section{Data collection}

All patients were subjected to complete blood count including RDW, liver function test, prothrombin time and concentration, international normalized ratio (INR) and abdominal US. The PV diameter was measured using US and the patients were classified according to whether they had PV dilatation and not. PV diameter was used as an indicator for portal hypertension [19]. They were divided into three groups according to Child's score (A, B, C) which is used as an indicator for liver cell function. Also they were classified according to whether they were receiving $\beta$-blockers or not.

\section{Statistical analysis}

All the data analysis was performed using performed using SPSS version software (SPSS Inc., Chicago, Illinois, USA). Continuous variables were expressed as mean value $\pm \mathrm{SD}$, and categorical data were reported as percentages. Any value of $P$ less than 0.05 was considered statistically significant.

\section{Results}

A total of 147 patients were enrolled in the study. Of them, 108 were men and 39 were women. Regarding age, 58 patients were between 50 and 60 years; 53 patients were $60-70$ years; 13 patients were between 40 and 50 years; 10 patients were between 70 and 80 years. Five patients were between 80 and 90 years. Four patients were between 30 and 40 years. Another four patients were between 10 and 20 years; 31 of them had low RDW, 25 high, and 91 had normal $\mathrm{RDW}$ with mean $\pm \mathrm{SD}$ (range): $13.19 \pm 1.82$ (9.8-19.4).

Prothrombin time (PT) was prolonged in 127 patients and was normal in 20 patients with mean $\pm \mathrm{SD}$ (range): $18.63 \pm 4.84$ (11.7-45.8). INR increased in 122 patients and was normal in 25 patients with mean $\pm \mathrm{SD}$ (range) of $1.55 \pm 0.40 \quad(0.99-3.92)$. Total bilirubin (TB) increased in 122 patients and was normal in 25 patients with mean \pm SD of $101.51 \pm 123.29$ and median (range) of 50.7 (2.1-712.4). A total of 135 patients had hypoalbuminemia, and 12 patients had normal albumin level with mean $\pm \mathrm{SD}$ (range) of 25.26 \pm 6.56 (13.9-45.2). Eighteen patients had mild ascites, 41 patients had moderate, and 35 patients had marked ascites, and 53 patients had no ascites. The PV was dilated in 39 patients and not dilated in 64 patients; 23

\section{Figure 1}

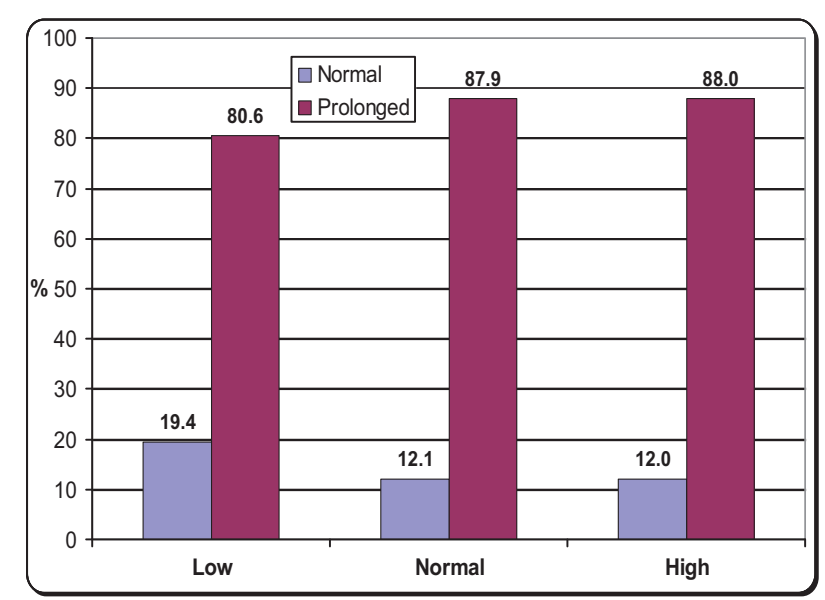

Prothrombin time.

Table 1 Correlation of red cell distribution width with coagulation profile, liver function, and Child's score

\begin{tabular}{lcc}
\hline & \multicolumn{2}{c}{ RDW } \\
\cline { 2 - 3 } & $r$ Value & $P$ value \\
\hline PT & 0.200 & $0.015^{*}$ \\
INR & 0.189 & $0.022^{*}$ \\
TB & 0.210 & $0.011^{*}$ \\
ALB & -0.173 & $0.036^{*}$ \\
Child's score & 0.221 & $0.007^{*}$ \\
\hline
\end{tabular}

ALB, albumin; INR, international normalized ratio; PT, prothrombin time; PV, portal vein; RDW, red cell distribution width; TB, total bilirubin. 
Figure 2

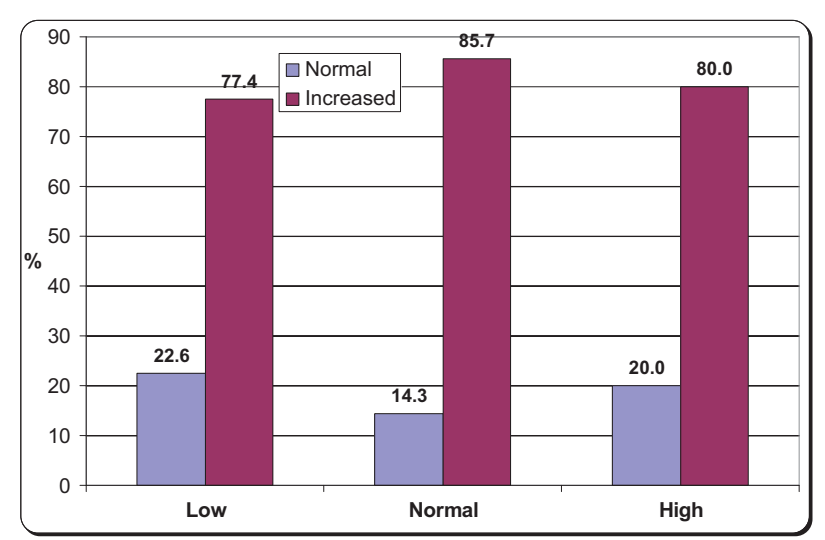

International normalized ratio.

patients had grade I, 15 patients had grade II, 11 patients had grade III, and eight patients had grade IV hepatic encephalopathy, but 90 patients were not suffering from encephalopathy.

Seven patients were receiving $\beta$-blockers, but 140 were not. Patients were classified according to Child-Pugh score. Eleven patients were of Child A; 56 were of Child B; and 80 were of Child $\mathrm{C}$ with mean $\pm \mathrm{SD}$ (range) of $9.74 \pm 2.07$ (5.0-14.0). RDW was low in $19.4 \%$ of patients with normal PT; it was normal in $12.1 \%$; and was high in $12 \%$ of them, but was low in $80.6 \%$ of patients with prolonged PT. RDW was normal in $87.9 \%$ and high in $88 \%$ of them (Fig. 1). There were significant correlation between RDW and the prolongation of PT $(P=0.015)$ (Table 1). RDW was low in $22.6 \%$ who had normal INR, normal in $14.4 \%$ and high in $20 \%$ of them, but was low in $77.4 \%$ of patients with increased INR, normal in $85.7 \%$, and high in $80 \%$ of them (Fig. 2). There were significant correlation between RDW and INR $(P=0.022)$ (Table 1).

RDW was low in $25.8 \%$ of patients with normal TB level, normal in $17.6 \%$, and high in $4 \%$ of them, but was low in $74.2 \%$ of patients who had increased TB level, normal in $82.4 \%$, and high in $96 \%$ of them (Fig. 3). There were significant correlation between RDW and TB $(P=0.011)$ (Table 1$)$. RDW was low in $77.4 \%$ of patients with hypoalbuminemia, normal in $96.7 \%$, and high in $92 \%$ of them. In patients with normal albumin level, 22.6\% had low RDW, 3.3\% had normal, and 8\% had high RDW (Fig. 4). There were significant correlation between RDW and albumin level $(P=0.036)$ (Table 1).

RDW was low in $48.4 \%$ in patients who had no ascites, normal in $35.2 \%$, and high in $24 \%$. In patients who had mild ascites, $12.9 \%$ had low, $11 \%$ had normal, and $16 \%$ had high RDW. In cases with moderate ascites, $22.6 \%$ had low, $29.7 \%$ had normal, and $28 \%$ had high RDW. In cases with marked ascites, $16.1 \%$ had low, $22 \%$ had normal, but $32 \%$ had high RDW, so there were significant correlation between RDW and degree of ascites $(P=0.590)$ (Fig. 5).

\section{Ascites}

RDW was low in $26.1 \%$ of patients with PV dilatation, normal in $44.3 \%$ and high in $31.6 \%$. But in patients who did not have PV dilatation, $73.9 \%$ had low, $55.7 \%$ had normal and $68.4 \%$ had high RDW, so there were no significant correlation between RDW and PV dilatation $(P=0.255)$ (Fig. 6).

RDW was low in $77.4 \%$ in patients who had no hepatic encephalopathy, normal in $57.1 \%$, and high in $56 \%$. In patients with grade I encephalopathy, $12.9 \%$ had low, $16.5 \%$ had normal, and 16\% had high RDW. In patients with grade II encephalopathy, 3.2\% had low, $13.2 \%$ had normal, and $8 \%$ had high RDW. In patients with grade III encephalopathy, $6.5 \%$ had low, $5.5 \%$ had normal, and $16 \%$ had high RDW. In patients with grade IV encephalopathy, $0 \%$ had low, $7.7 \%$ had normal, and $4 \%$ had high RDW, so there were no significant correlation between RDW and the degree of hepatic encephalopathy, but there were significant correlation between low RDW and patients with no encephalopathy $(P=0.276)$ (Fig. 7).

RDW was low in $3.2 \%$ of patients who was receiving $\beta$-blockers, normal in 6.6\%, and high in $0 \%$. But was low in $96.8 \%$, normal in $93.4 \%$, and high in $100 \%$ of patients who did not receive $\beta$-blockers, so there were significant correlation between $\mathrm{RDW}$ and patients who receive $\beta$-blockers ( $P=0.353$ ) (Fig. 8).

RDW was low in $19.4 \%$ of patients with Child A, normal in 4.4\% and high in 4\%. In Child B, 38.7\% had low, $41.8 \%$ had normal, and $24 \%$ had high RDW. In Child C, 41.9\% had low, 53.8\% had normal, and 72\% had high RDW (Fig. 9). There were significant correlation between RDW and the grade of Child's score $(P=0.007)$ (Table 1$)$.

\section{Discussion}

In the current study we found the mean age was between 40 and 70 and RDW tends to be normal in $61 \%$ of patients. About $36 \%$ had no ascites and $61 \%$ had no encephalopathy that may be due to good 
Figure 3

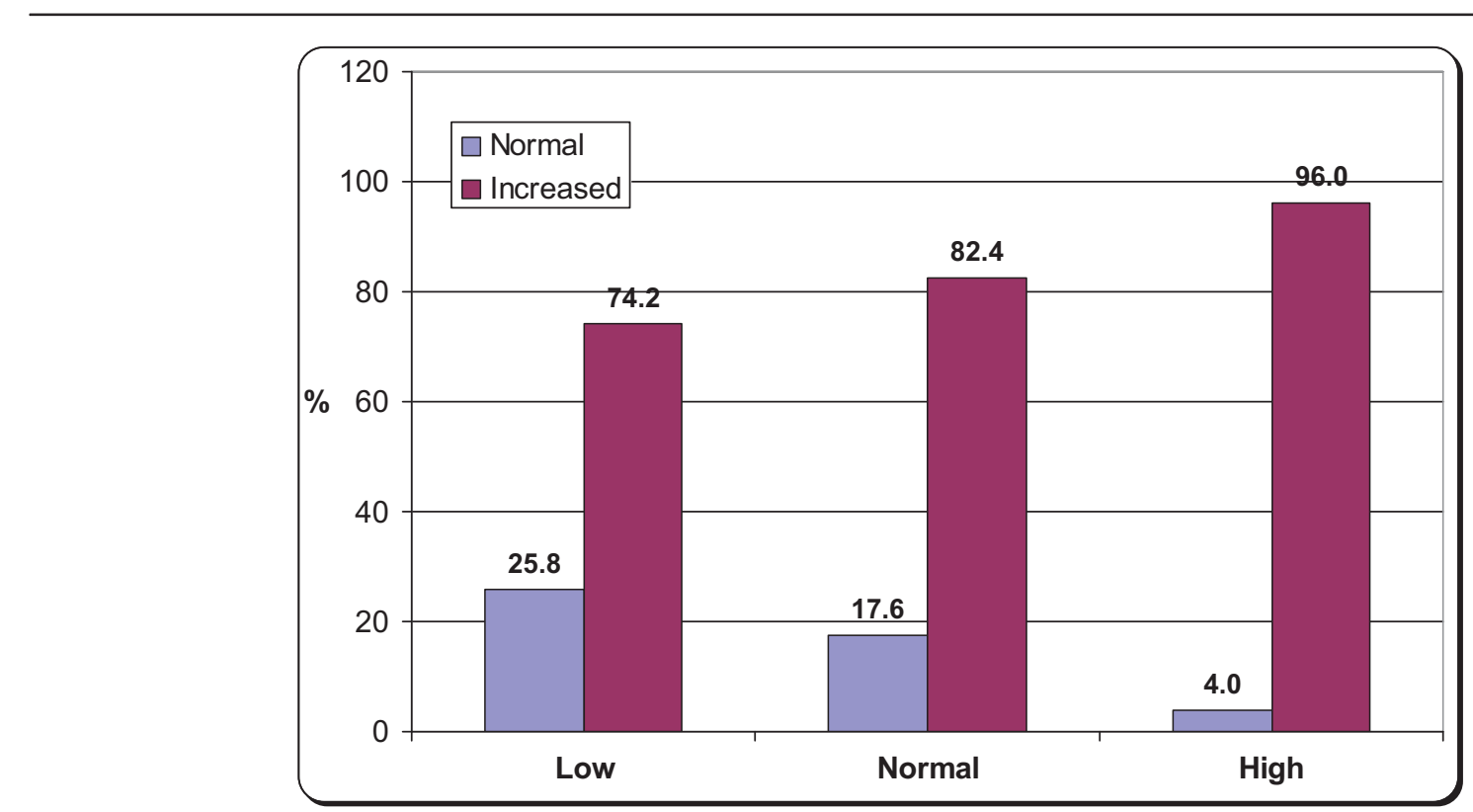

Total bilirubin.

\section{Figure 4}

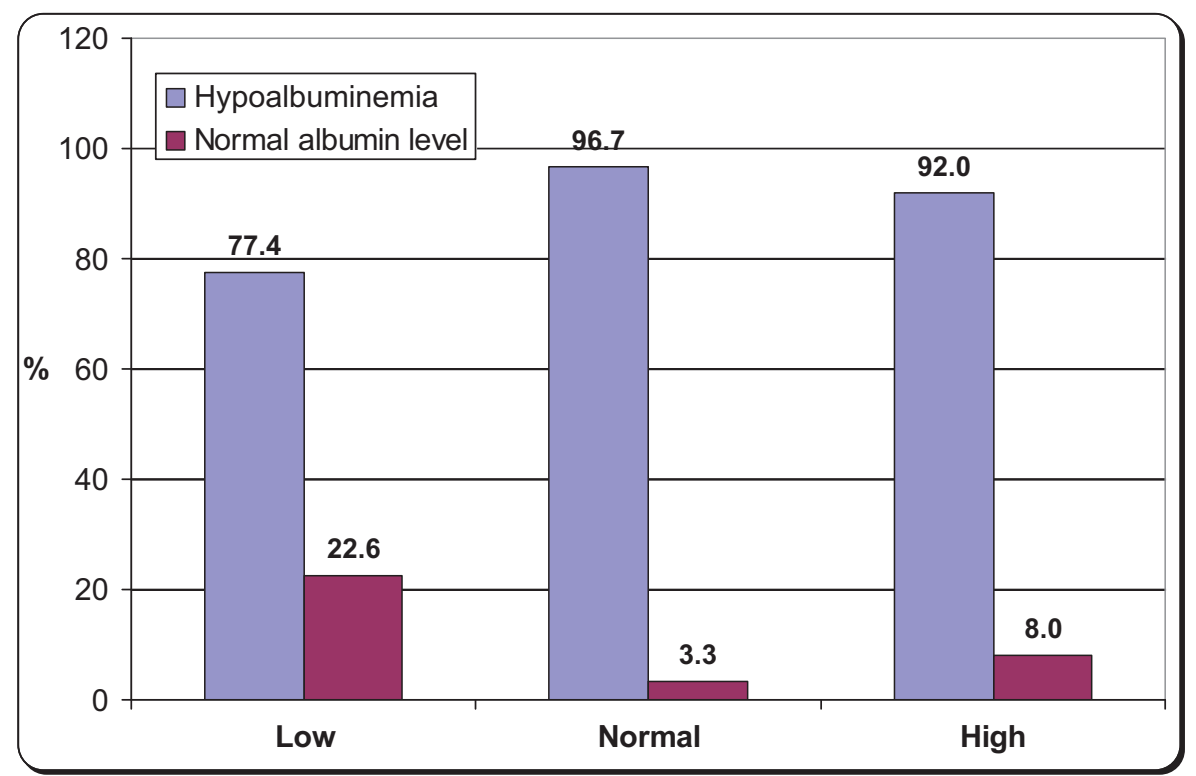

Albumin.

compliance for medical treatment and regular follow-up, but about $95 \%$ did not receive $\beta$-blockers, which was missed in most of the prescriptions. We found that RDW values in most of the cirrhotic patients were positively correlated with PT, INR, TB, hypoalbuminemia, and amount of ascites. RDW reflects the variability in circulating $\mathrm{RBC}$ size. It is based on the width of the RBC volume distribution curve, with larger values indicating greater variability [20]. The liver is the largest organ in the body and is responsible for filtering harmful chemical substances; accumulation of toxins may affect the size of RBCs and therefore the RDW values. Thus, we speculate that this is an important factor that influences disease progression, and may present an important predictor index for LCF. Recently, several studies have investigated the association between $\mathrm{RDW}$ and the severity of chronic liver diseases including nonalcoholic fatty liver disease, alcoholic cirrhosis, and primary biliary cirrhosis [21-26]. However, Milic et al. [26] found that a statistically significant increase in RDW relevant to the disease severity was not observed in neither in groups of patients with alcoholic cirrhosis nor with nonalcoholic cirrhosis. 


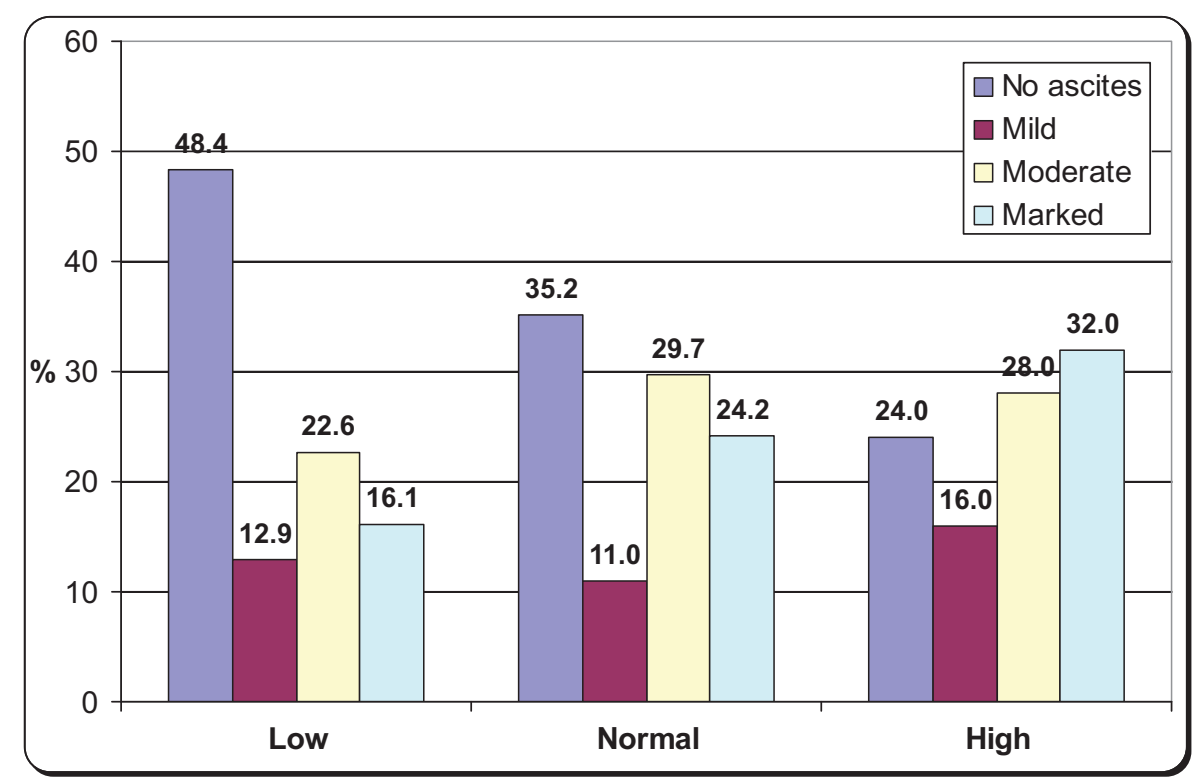

Ascites.

Figure 6

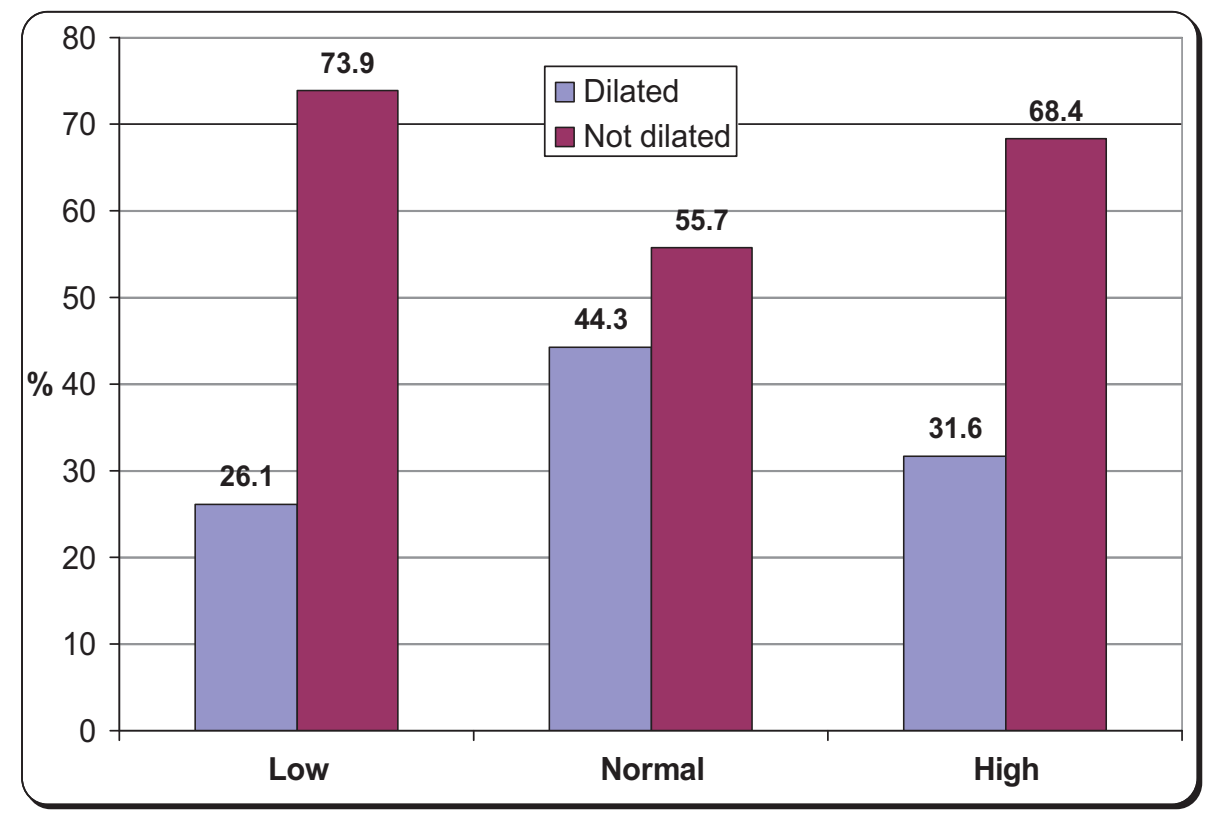

Portal vein.

Lou et al. [27] reported the association between RDW values and $\mathrm{HBV}$-infected patients of different disease states and they found that the RDW values were increased in patients with hepatitis B significantly and associated with its severity. However, patients with HBV-related LC were not included in their study. In the present study, we investigated the association between RDW values and LCF and portal hypertension in LC despite its cause. A recent study has shown that RDW is correlated with hepatocellular carcinoma [26]. Liver fibrosis is characterized by a continuous wound-healing response and chronic inflammation. Recently, in a large unselected cohort of patients, RDW showed a strong and graded association with inflammatory markers, which was independent of ferritin, age, sex, and other hematological variables [28]. Inflammation might contribute to increased RDW values not only by impairing iron metabolism but also by inhibiting the production of response to erythropoietin or by shortening RBC survival $[29,30]$. A number of studies have shown that proinflammatory cytokines 
Figure 7

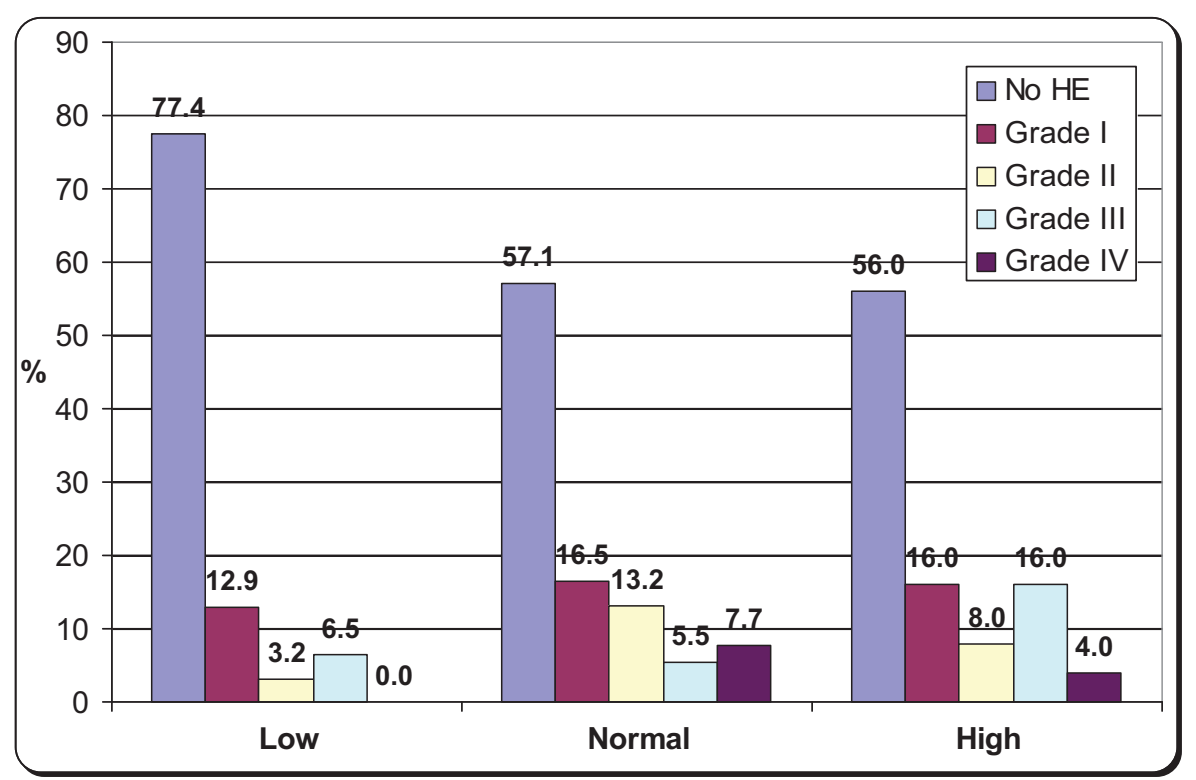

Hepatic encephalopathy.

\section{Figure 8}

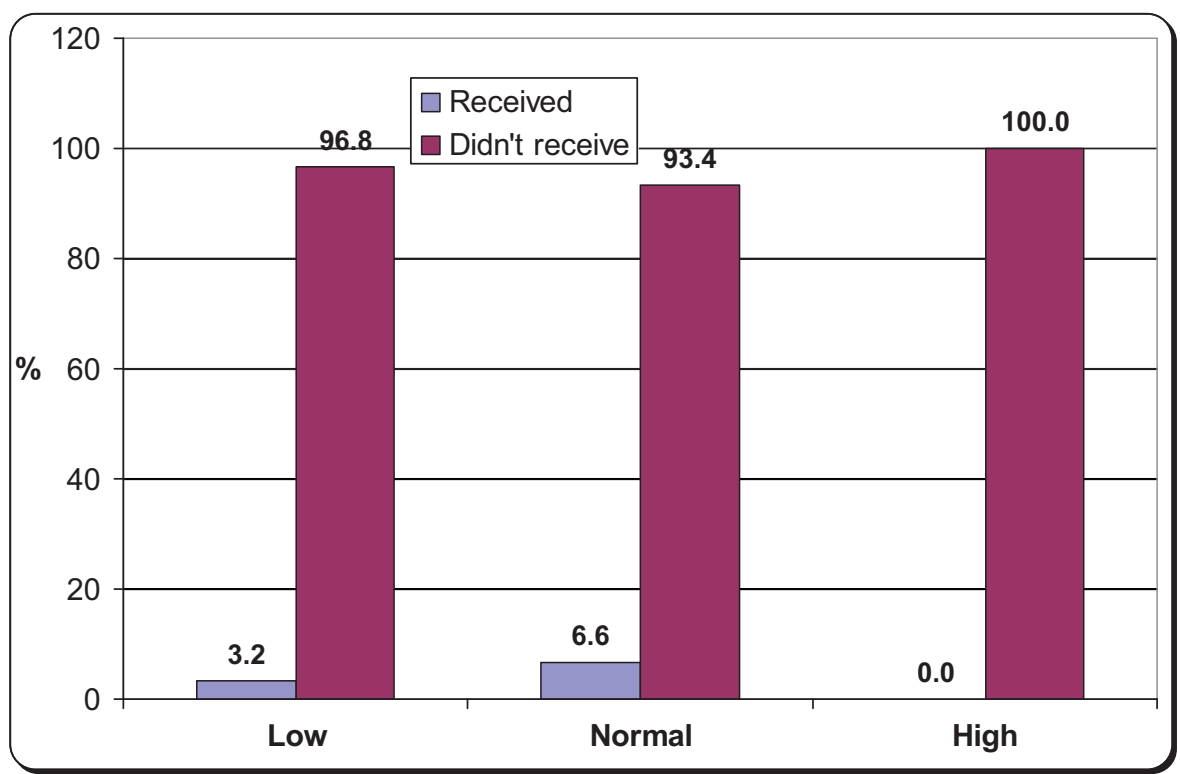

Receiving $\beta$-blocker.

suppress erythropoietin gene expression, inhibit proliferation of erythroid progenitor cells, downregulate erythropoietin receptor expression, and reduce erythrocyte life span [31].

During the inflammation response, many kinds of inflammatory cytokines may suppress erythrocyte maturation and allow larger, newer reticulocytes to enter the circulation, thus resulting in increased RDW values [32,33]. Red cell distribution is typically elevated in conditions of increased red cell destruction and bone marrow depression [34,35].
Anemia is a common complication in patients with advanced liver diseases [36,37]. When portal hypertension occurs in patients with chronic liver diseases, the spleen frequently enlarges and thus reduces the numbers of RBCs in the blood $[38,39]$. These may be another mechanism that causes increased RDW values in patients with $L C$.

The study also indicated an increasing correlation of RDW values with worsening of Child-Pugh score. Thus, the RDW values may be associated with the survival of patients suffering from cirrhosis. The 


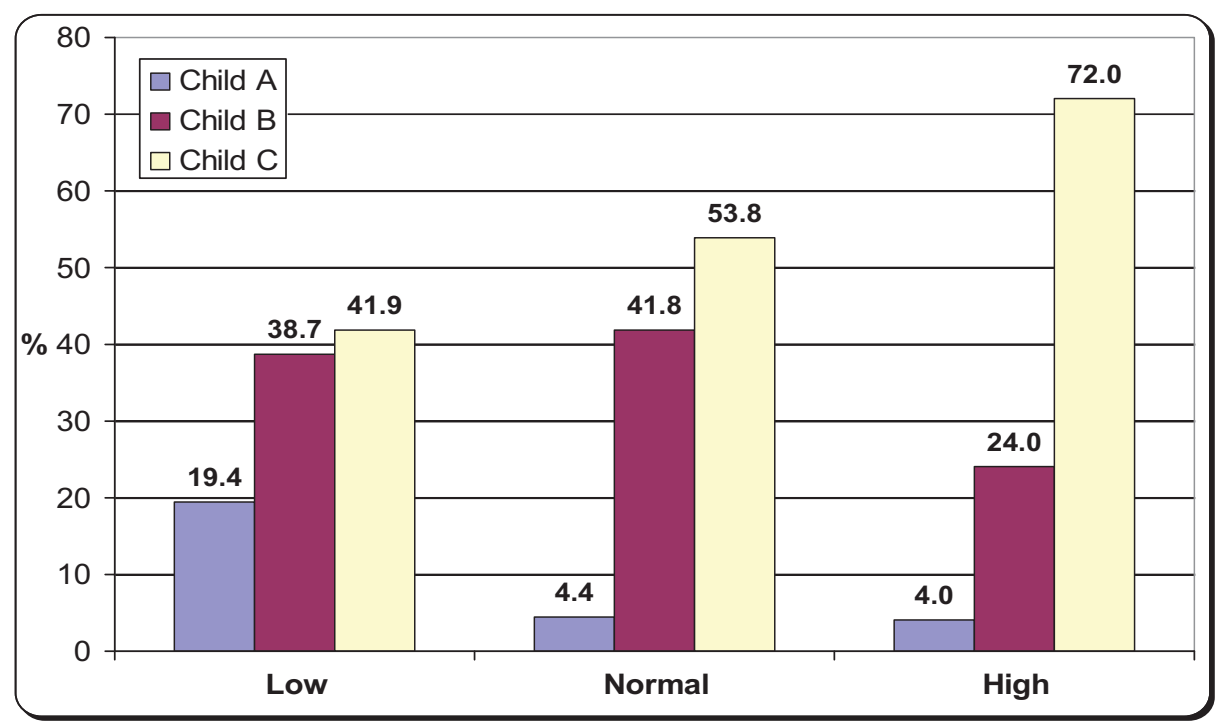

Childs score.

Child-Pugh score was originally developed as an indicator of perioperative mortality in patients with $\mathrm{LC}$ and is most widely used to classify liver impairment and predict the survival of patients suffering from cirrhosis [24]. The study indicated an increasing correlation of RDW values with worsening of Child-Pugh score; hence mortality in patients with LC. Hu and colleagues observed that RDW levels are positively related to Child-Pugh and model for endstage liver disease scores among patients with HBVrelated LC [21,24]. Also we found that RDW is significantly low in patients with no hepatic encephalopathy, but no significant correlation with the grade of encephalopathy which merits further investigation. Increased resistance to portal blood flow due to alteration of the hepatic architecture leads to dilatation of PV, splenomegaly, and formation of esophageal and gastric varices, variceal hemorrhage, ascites, hypersplenism, encephalopathy, etc. In cirrhosis, increased intrahepatic vascular resistance is thought to be located mainly in the hepatic sinusoids. Recent studies have demonstrated that in addition to the increased resistance caused by the morphologic change of chronic liver diseases, a dynamic component of increased resistance (resulting from the active contraction of vascular smooth muscle cells, myofibroblasts, and hepatic stellate cells) is also present. Portal hypertension leads to the dilatation of PV, splenomegaly, and formation of portal systemic collaterals at different sites. In our study patients with LCF had no significant RDW values with PV dilatation. It is still more or less normal, but was significantly low in cirrhotic patients who did not have PV dilatation which must be investigated in a wider study. Also we found that RDW is highly significantly high in patients who had not received $\beta$-blockers; so it may be used as an indicator for patient compliance. $\beta$-Blockers, which include propranolol, nadolol, and timolol, are used to provide primary and secondary prophylaxis. $\beta$-Blockers lower the cardiac output (via blockade of $\beta 1$ adrenoreceptors) and cause splanchnic vasoconstriction (via blockade of vasodilatory adrenoreceptors of the splanchnic circulation), reducing portal and collateral blood flow. Nonselective $\beta$-adrenergic blockers have been shown to reduce the risk of first variceal bleeding (from 24 to $15 \%$ after a median follow-up of 2 years) and mortality (from 27 to 23\%) [40], which show the importance of using RDW as an indicator for patient compliance. Some limitations of this study warrant consideration. First, we did not investigate the causes of elevated RDW values, such as folate and vitamin B12 deficiency, which could confound the association between RDW values and adverse outcome. Second, this was a single-center study.. Therefore, our findings need to be confirmed in multicenter and prospectively designed studies. RDW values were not dynamically observed, and thus whether RDW values elevated stepwise when patient's condition progressively deteriorated or whether it improved when the patient received antiviral treatment. Also the prognostic value of RDW in patients with different causes of LC merits further investigation. Despite these limitations, we found significantly elevated RDW values in patients with LCF. RDW is an independent predictor of noninvasive index of LCF in LC which was the aim of our study. Because RDW values are easily attainable 
at no additional cost to the routine complete blood cell counts and is highly reproducible, it may serve as an important biomarker. A good correlation between worsening of Child-Pugh and RDW values was also found. A strong correlation between high RDW and patient did not receive $\beta$-blocker, so it may be used as an indicator for compliance. There was no significant correlation between RDW and PV diameter and so portal hypertension. Also there was no significant correlation between RDW and grade of hepatic encephalopathy.

\section{Conclusion and recommendation}

In conclusion, our study shows that RDW could provide useful information with other serum markers for the detection of LCF in LC. We found significantly good correlation between Child-Pugh and RDW values which can ultimately be used to predict the survival of patients with LC. There was also good correlation between RDW and those receiving $\beta$-blockers, so it may be used as an indicator for patient compliance, but there was no significant correlation with the grade of encephalopathy and portal hypertension.

Our study should be further assessed by prospective studies with larger patient populations involving multiple centers. Investigating the causes of elevated RDW values such as folate and vitamin B12 deficiency is recommended. The role of RDW if the condition of the patient is progressively deteriorated or even if improved when the patient received antiviral treatment should be also further evaluated in another study. Also the prognostic value of RDW in patients with different causes of LC merits further evaluation. Searching for another biochemical index for predicting portal hypertension is recommended.

\section{Financial support and sponsorship Nil.}

\section{Conflicts of interest}

There are no conflicts of interest.

\section{References}

1 Lozano R, Naghavi M, Foreman K, Lim S, Shibuya K, Aboyans V, et al. Global and regional mortality from 235 causes of death for 20 age groups in1990 and 2010: a systematic analysis for the Global Burden of Disease Study 2010. Lancet 2012; 380:2095-2128.

2 Mehta SH, Lau B, Afdhal NH, Thomas DL, et al. Exceeding the limits of liver histology markers. J Hepatol 2009; 50:36-41.

3 Bosch J. Vascular deterioration in cirrhosis: the big picture. J Clin Gastroenterol 2007; 41(Suppl 3):S247-S253.

4 Iwakiri Y, Groszmann RJ. The hyperdynamic circulation of chronic liver diseases: from the patient to the molecule. Hepatology 2006; 43: S121-S131.
5 Perkins SL. Examination of blood and bone marrow. In: Greer JP, Foerster J, Lukens JN, Paraksevas F, Glader BE, editors. Wintrobe's clinical hematology. UT: Lippincott Wilkins \& Williams; 2003. pp. 5-25.

6 Bessman JD, Hurley EL, Groves MR. Nondiscrete heterogeneity of human erythrocytes: comparison of Coulter-principle flow cytometry and Sorethemoglo-binometry image analysis. Cytometry 1983; 3:292-295.

7 England JM, Down MC. Red-cell-volume distribution curves and the measurement of anisocytosis. Lancet 1974; 1:701-703.

8 Demir A, Yarali N, Fisgin T, Duru F, Kara A. Most reliable indices in differentiation between thalassemia trait and iron deficiency anemia. Pediatr Int 2002; 44:612-616.

9 Felker GM, Allen LA, Pocock SJ, Shaw LK, McMurray JJ, Pfeffer MA, et al. CHARM Investigators. Red cell distribution width as a novel prognostic marker in heart failure: data from the CHARM Program and the Duke Databank. J Am Coll Cardiol 2007; 50:40-47.

10 Förhécz Z, Gombos T, Borgulya G, Pozsonyi Z, Prohászka Z, Jánoskuti L, et al. Red cell distribution width in heart failure: prediction of clinical events and relationship with markers of ineffective erythropoiesis, inflammation, renal function, and nutritional state. Am Heart J 2009; 158:659-666.

11 Pascual-Figal DA, Bonaque JC, Redondo B, Caro C, Manzano-Fernandez $\mathrm{S}$, Sánchez-Mas J, et al. Red blood cell distribution width predicts long-term outcome regardless of anaemia status in acute heart failure patients. Eur $\mathrm{J}$ Heart Fail 2009; 11:840-846.

12 Tonelli M, Sacks F, Arnold M, Moye L, Davis B, Pfeffer M, et al. For the Cholesterol and Recurrent Events (CARE) Trial Investigators. Relation between red blood cell distribution width and cardiovascular event rate in people with coronary disease. Circulation 2008; 117:163-168.

13 Dabbah S, Hammerman H, Markiewicz W, Aronson D. Relation between red cell distribution width and clinical outcomes after acute myocardial infarction. Am J Cardiol 2010; 105:312-317.

14 Ani C, Ovbiagele B. Elevated red blood cell distribution width predicts mortality in persons with known stroke. J Neurol Sci 2009; 277:103-108.

15 Hampole CV, Mehrotra AK, Thenappan T, Gomberg MM, Maitland M, Shah S, et al. Usefulness of red cell distribution width as a prognostic marker in pulmonary hypertension. Am J Cardiol 2009; 104:868-872.

16 Perlstein TS, Weuve J, Pfeffer MA, Beckman JA. Red blood cell distribution width and mortality risk in a community based prospective cohort. Arch Intern Med 2009; 169:588-594.

17 Patel KV, Ferrucci L, Ershler WB, Longo DL, Guralnik JM. Red blood cell distribution width and the risk of death in middle-aged and older adults. Arch Intern 2009; Med169:515-523.

18 Chen PC, Sung FC, Chien KL, Hsu HC, Su TC, Lee YT, et al. Red blood cell distribution width and risk of cardiovascular events and mortality in a community cohort in Taiwan. Am J Epidemiol 2010;171:214-220.

19 Lebrec D, Nouel O, Corbic M, Benhamou JP. Propranolol - a medical treatment for portal hypertension?. Lancet 1980; 2:180-182.

20 Huo TI, Wu JC, Lin HC, Lee FY, Hou MC, Lee PC, et al. Evaluation of the increase in model for end-stage liver disease (DMELD) score over time as a prognostic predictor in patients with advanced cirrhosis: risk factor analysis and comparison with initial MELD and Child-Turcotte-Pugh score. J Hepatol 2005; 42:826-832.

21 Hu Z, Sun Y, Wang Q, Han Z, Huang Y, Liu X, et al. Red blood cell distribution width is a potential prognostic index for liver disease. Clin Chem Lab Med 2013; 51:1403-1408.

22 Milić S, Mikolasević I, Radić M, Hauser G, Stimac D. Clinical utility of red cell distribution width in alcoholic and non-alcoholic liver cirrhosis. Coll Antropol 2011; 35 (Suppl 2):335-338.

$23 \mathrm{Kim} \mathrm{HM}$, Kim BS, Cho YK, Kim BI, Chong II Sohn, Jeon WK, et al. Elevated red cell distribution width is associated with advanced fibrosis in NAFLD. Clin Mol Hepatol 2013; 19:258-265.

24 Huang R, Yang C, Wu K, Cao S, Liu Y, Su R, et al. Red cell distribution width as a potential index to assess the severity of hepatitis $B$ virus-related liver diseases. Hepatol Res 2014;44:E464-E470.

25 Shiha G, Sarin SK, Ibrahim AE, Omata M, Kumar A, Lesmana L, et al. Liver fibrosis: consensus recommendations of the Asian Pacific Association for the Study of the Liver (APASL). Hepatol Int 2009; 3:323-333.

26 Milic S, Mikolasevic I, Radic M, Hauser G, Stimac D, et al. Clinical utility of red cell distribution width in alcoholic and non-alcoholic liver cirrhosis. Coll Antropol 2012; 35(Suppl 2):335-338.

27 Lou Y, Wang M, Mao W. Clinical usefulness of measuring red blood cell distribution width in patients with hepatitis B. PLoS One 2012; 7: e37644. 
28 Goyal H, Lippi G, Gjymishka A, John B, Chhabra R, May E. Prognostic significance of red blood cell distribution width in gastrointestinal disorders. World J Gastroenterol. 2017; 23:4879-4891.

29 Mao W, Ye B, Lin S, Fu Y, Chen Y. The prediction value of MELD scoring system on prognosis in the acute on chronic liver failure patients with artificial liver support system. ASAIO 2010; 56:475-478.

30 Lippi G, Targher G, Montagnana M, Salvagno GL, Zoppini G, Guidi GC, et al. Relation between red blood cell distribution width and inflammatory biomarkers in a large cohort of unselected outpatients. Arch Pathol Lab Med 2009; 133:628-632.

31 Rogiers $\mathrm{P}$, Zhang $\mathrm{H}$, Leeman $\mathrm{M}$, Nagler J, Neels $\mathrm{H}$, Mélot $\mathrm{C}$, Vincent JL, et al. Erythropoietin response is blunted in critically ill patients. Intensive Care Med 1997; 23:159-162.

32 Pierce CN, Larson DF. Inflammatory cytokine inhibition of erythropoiesis in patients implanted with a mechanical circulatory assist device. Perfusion 2005; 20:83-90.

33 Karnad A, Poskitt TR. The automated complete blood cell count. Use of the red blood cell volume distribution width and mean platelet volume in evaluating anemia and thrombocytopenia. Arch Intern Med 1985; $145: 1270-1272$
34 Evans TC, Jehle D. The red blood cell distribution width. J Emerg Med 1991; 9 (Suppl 1):71-74.

35 McHutchison JG, Manns MP, Longo DL. Definition and management of anemia in patients infected with hepatitis $C$ virus. Liver Int 2006; 26:389-398.

36 Gonzalez-Casas R, Jones EA, Moreno-Otero R. Spectrum of anemia associated with chronic liver disease. World J Gastroenterol 2009; 15:4653-4658.

37 Bolognesi M, Merkel C, Sacerdoti D, Nava V, Gatta A. Role of spleen enlargement in cirrhosis with portal hypertension. Dig Liver Dis 2002; 34:144-150.

38 Shah SH, Hayes PC, Allan PL, Nicoll J, Finlayson ND. Measurement of spleen size and its relation to hypersplenism and portal hemodynamics in portal hypertension due to hepatic cirrhosis. Am J Gastroenterol 1996; 91:2580-2583.

39 Pugh RN, Murray-Lyon IM, Dawson JL, Pietroni MC, Williams R. Transection of the oesophagus for bleeding oesophageal varices. $\mathrm{Br} J$ Surg 1973; 60:646-649.

40 D'Amico G, Pagliaro L, Bosch J. Pharmacological treatment of portal hypertension: an evidence-based approach. Semin Liver Dis 1999; 19:475-505. 